\title{
HYPONATREMIA AS A PROGNOSTIC INDICATOR IN LOWER RESPIRATORY TRACT INFECTIONS IN CHILDREN ADMITTED IN PAEDIATRIC INTENSIVE CARE UNIT
}

\author{
Naila Hamid, Muhammad Faisal Shafique*, Qamar-Uz-Zaman, Hafsa Niaz \\ Pak Emirates Military Hospital/National University of Medical Sciences (NUMS) Rawalpindi Pakistan, *Combined Military Hospital/National University of \\ Medical Sciences (NUMS) Rawalpindi Pakistan
}

\begin{abstract}
Objective: To study the serum sodium levels in patients of lower respiratory tract infections admitted in the paediatric intensive care unit with their prognosis.

Study Design: Prospective observational study.

Place and Duration of Study: Pak Emirates Military Hospital Rawalpindi, from Jan to Jun 2018.

Methodology: Eighty patients suffering from lower respiratory tract infections who were admitted to the paediatric intensive care unit were selected at consecutive sampling. The outcome was recorded in the form of discharge or mortality. Serum sodium was done at the time of admission and then periodically after every 24-48 hours. The Association of patients' serum sodium with their prognosis was studied using chi-square test and $p$-value was calculated.

Results: A total of 80 patients were enrolled in our study out of which $50(62.50 \%)$ were males and $30(37.50 \%)$ were females. Out of the total, 48 patients suffered from hyponatremia. These 48 patients had a mean serum sodium concentration of 131.24 $\pm 3.31 \mathrm{mEq} / \mathrm{L}$. The mean age of patients suffering from hyponatremia was $5.78 \pm 3.4$ years. Mortality occurred in $5(80.12 \%)$ of patients suffering from severe hyponatremia.

Conclusion: There was a significant association of hyponatremia with mortality in children admitted in paediatric intensive care settings with lower respiratory tract infections. Therefore, proper management hence correction of serum sodium levels can improve survival in, particularly children admitted in a pediatric intensive care setting.
\end{abstract}

Keywords: Hospital mortality, Morbidity, Paediatric intensive care unit, Prognosis, Respiratory infections.

How to Cite This Article: Hamid N, Shafique MF, Zaman Q, Niaz H. Hyponatremia as A Prognostic Indicator in Lower Respiratory Tract Infections in Children Admitted in Paediatric Intensive Care Unit. Pak Armed Forces Med J 2021; 71(5): 1590-1593. doi: https://doi.org/10.51253/pafmj.v71i5.3477

This is an Open Access article distributed under the terms of the Creative Commons Attribution License (https://creativecommons.org/licenses/by-nc/4.0/), which permits unrestricted use, distribution, and reproduction in any medium provided the original work is properly cited.

\section{INTRODUCTION}

Lower respiratory tract infections are the most common cause of mortality and morbidity in developing countries like Pakistan. ${ }^{1}$ Lower respiratory tract infections mainly include acute bronchiolitis and pneumonia. Bronchiolitis is an illness of the paediatric age group caused mainly by a respiratory syncytial virus (RSV). About $1 \%$ of children with acute bronchiolitis require hospitalization because of dehydration, failure to feed or severe respiratory distress. Between 10-15\% of all hospitalized children with lower respiratory tract infections will require intensive care due to impending respiratory failure., ${ }^{2}$ Pneumonia is one of the leading causes of death $(20-25 \%)$ in the pediatric age group especially under 5 years. ${ }^{3}$

Acute bronchiolitis is defined as lower respiratory tract infection caused by viruses manifesting as wheeze and bilateral crept, low-grade fever and low to moderate elevation in total leukocyte count and no radiographic evidence of pneumonia. ${ }^{4}$ Serum sodium

Correspondence: Dr Naila Hamid, Department of Paediatrics, Pak Emirates Military Hospital, Rawalpindi Pakistan

Received: 11 Sep 2019; revision received: 27 Apr 2020; accepted: 30 Apr 2020 levels (normal and deranged) were taken as: normalnatremia: sodium levels $135-145 \mathrm{mEq} / \mathrm{L}$, mild hyponatremia: sodium levels 131-134 mEq/L, moderate hyponatremia: sodium levels $126-130 \mathrm{mEq} / \mathrm{L}$, and severe hyponatremia: sodium level $<126 \mathrm{mEq} / \mathrm{L} .^{5}$

Hyponatremia is one of the most common and frequent electrolyte abnormalities seen in hospitalized and critically ill children. ${ }^{4}$ Hyponatremia occurs frequently in hospitalized patients with lower respiratory tract infection with frequency documented as high as $30 \% .{ }^{5}$ some studies support the significance of hyponatremia as a prognostic factor in defining the severity of lower respiratory tract infections. 7,8

There are very few studies from PICU in Pakistan on the subject. 9,10 The objective of this study was to analyze the sodium levels in children of various age groups admitted in PICU with lower respiratory tract infections and document the outcome.

\section{METHODOLOGY}

This prospective observational study was conducted in Pediatric Intensive Care Unit of Pak Emirates Military Hospital, Rawalpindi from January to June 2018. Eighty patients suffering from lower respiratory 
tract infections who were admitted in PICU were selected through consecutive sampling. Sample size was calculated using an online calculator (openepi.com) for calculating sample size using the confidence interval of $95 \%$ and prevalence of hyponatremia in paediatric ICU admitted patients of $80 \%$ in a reference study done in Nepal by Tamrakar et al. They were prospectively studied till discharge or death. Outcome was recorded in the form of discharge or mortality. Ethics approval was sought from Pak Emirates Military Hospital Ethical Review Committee (A/28/08/EC).

All the patients selected were fully informed regarding their participation in the study and informed consent was taken from their parents.

Inclusion Criteria: The patients included were those diagnosed with lower respiratory tract infection as per World Health Organization definition. Age group included was children $>1$ year of age up to 12 years. Diagnosis included acute bronchiolitis, pneumonia and chronic or recurrent chest infections manifesting in the form of bronchiectasis.

Exclusion Criteria: Those patients were excluded who were diagnosed with bronchopulmonary dysplasia, cystic fibrosis, bronchial asthma, recurrent respiratory infections secondary to congenital heart disease, patients with pneumonia and multi organ dysfunction secondary to severe sepsis, patients with pneumonia complicated with meningitis, central nervous system diseases such as cerebral palsy patients or post meningitis sequalae admitted with pneumonia.

Chi square test was applied and $p$-value was calculated using $2 \times 2$ contingency table in an online calculator (Graphpad prism). Descriptive statistics were calculated using SPSS-23 for windows. The variables for example total leukocyte count, C-reactive protein and length of stay in hospital as well as requirement of mechanical ventilation were studied as independent variables affecting outcome in hypona-tremics with lower respiratory tract infections mainly pneumonia.

\section{RESULTS}

There were 80 patients in our study out of which $48(60 \%)$ suffered from hyponatremia. Out of 48.36 $(75 \%)$ were males and $12(25 \%)$ were females. The mean age of patients suffering from hyponatremia was $5.78 \pm 3.4$ years. Maximum patients were admitted with a diagnosis of pneumonia $(76.25 \%)$. Out of eighty patients, $17(21.25 \%)$ patients required mechanical ventilation and out of $17,14(86.7 \%)$ were having hyponatremia, Overall mortality in the bronchiectasis group was found to be $3(50 \%)$ but all the patients with hyponatremia died due to complications (Table-I). According to our study there was a statistically significant association between hyponatremia and mortality ( $p=$ $0.046)$ and positive $C$ reactive protein $(p=0.046)$ but association between hyponatremics and their Total leukocyte count $>12000$, length of stay in hospital as well as their mechanical ventilation requirement was not significant $(p=0.91, p=0.301$ and $p=0.100$ respectively) shown in Table-II.

\begin{tabular}{|c|c|c|c|}
\hline Parameters & Pneumonia & \begin{tabular}{c|} 
Acute \\
Bronchiolitis
\end{tabular} & $\begin{array}{c}\text { Bron- } \\
\text { chiectasis }\end{array}$ \\
\hline Frequency & $61(76.25 \%)$ & $13(16.25 \%)$ & $6(7.5 \%)$ \\
\hline Hyponatremia & $35(57.37 \%)$ & $9(69.23 \%)$ & $4(67 \%)$ \\
\hline $\begin{array}{l}\text { Total Leukocyte } \\
\text { Count }>12000\end{array}$ & $49(80.32 \%)$ & $4(30.76 \%)$ & $6(100 \%)$ \\
\hline $\begin{array}{l}\text { Positive C } \\
\text { Reactive Protein }\end{array}$ & $58(95.08 \%)$ & $8(61.53 \%)$ & $4(67 \%)$ \\
\hline $\begin{array}{l}\text { Length of Stay } \\
>1 \text { week }\end{array}$ & $22(36.06 \%)$ & $11(84.61 \%)$ & $6(100 \%)$ \\
\hline $\begin{array}{l}\text { Mechanical } \\
\text { Ventilation }\end{array}$ & $4(6.5 \%)$ & $6(46.15 \%)$ & $3(50 \%)$ \\
\hline Mortality & $8(4.9 \%)$ & $3(23.07 \%)$ & $3(50 \%)$ \\
\hline
\end{tabular}

Table-II: Association of overall frequency of prognostic factors in normonatremia and hyponatremia groups.

\begin{tabular}{l|c|c|c}
\hline Parameters & $\begin{array}{c}\text { No Hyponat- } \\
\text { remia 32 }\end{array}$ & $\begin{array}{c}\text { Hyponat- } \\
\text { remia 48 }\end{array}$ & $\begin{array}{c}p- \\
\text { value }\end{array}$ \\
\hline $\begin{array}{l}\text { Total Leukocyte } \\
\text { Count }>12000\end{array}$ & $23(71.8 \%)$ & $35(72.9 \%)$ & 0.91 \\
\hline $\begin{array}{l}\text { Positive C } \\
\text { Reactive Protein }\end{array}$ & $6(18 \%)$ & $24(50 \%)$ & 0.046 \\
\hline $\begin{array}{l}\text { Length of Stay } \\
\text { >1 week }\end{array}$ & $5(15.6 \%)$ & $15(31.2 \%)$ & 0.301 \\
\hline $\begin{array}{l}\text { Mechanical } \\
\text { Ventilation }\end{array}$ & $3(9.3 \%)$ & $14(29.1 \%)$ & 0.100 \\
\hline Mortality & $2(6.2 \%)$ & $14(29.1 \%)$ & 0.046 \\
\hline
\end{tabular}

There were pneumonia in $61(76.25 \%)$ patients, acute bronchiolitis in $13(16.25 \%)$ patients and bronchiectasis in $6(7.5 \%)$ patients (Figure-1) and severity of pneumonia in patients with various diagnoses shown in the Figure-2.

\section{DISCUSSION}

Electrolyte abnormalities are frequently found in critically ill children and contribute to mortality and morbidity as also reported by Das et al, in their study carried out in India stating significant correlation between hyponatremia and morbidity $(p$-value $=0.003) \cdot{ }^{10}$ The common diseases in which hyponatremia is encountered are meningoencephalitis, acute gastroenteritis, pneumonia and bronchiolitis as reported by Sachdev et al in their study done in India that 


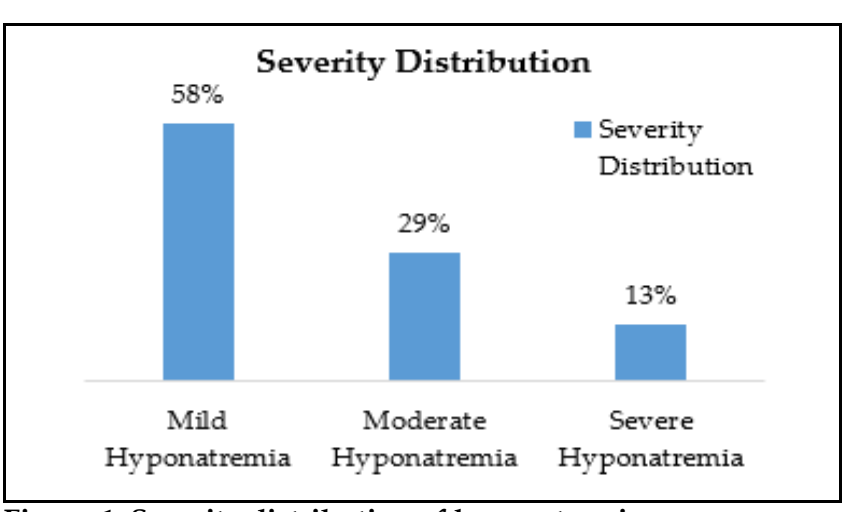

Figure-1: Severity distribution of hyponatremia.

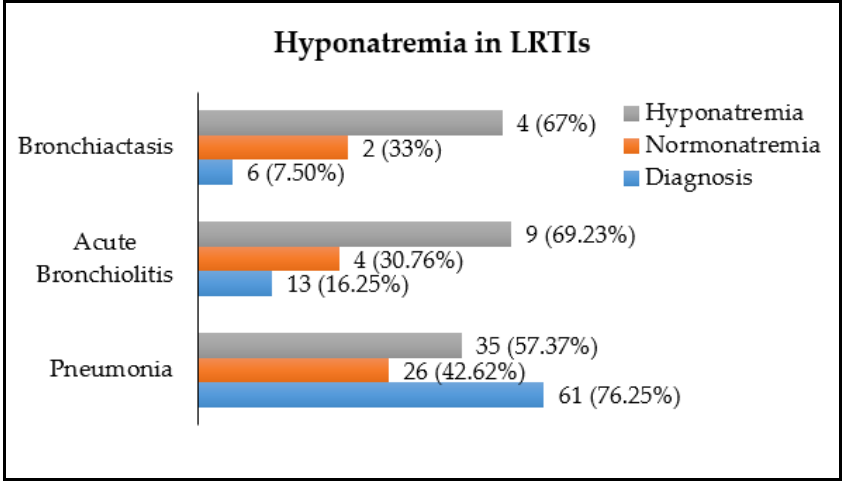

Figure-2: Severity of pneumonia in patients with various diagnoses.

hyponatremic patients with a diagnosis of meningoencephalitis were $35(28.45 \%)$, acute gastroenteritis were $17(13.82 \%)$, pneumonia were $28(22.76 \%)$ and acute bronchiolitis were 4 (3.25\%).

World Health Organization defines pneumonia as fever with tachypnea (respiratory rate greater than age-appropriate standards) and severe pneumonia as fever, tachypnea and subcostal recessions. Very severe disease is defined as pneumonia with danger signs (unconsciousness, cyanosis, failure to feed, convulsions). ${ }^{11-16}$

In our study, we encountered hyponatremia in $60 \%$ of the cases. Severe hyponatremia was encountered in $10(12.5 \%)$ of the critically ill patients while $70(87.5 \%)$ of patients suffered from mild to moderate hyponatremia. The percentage of patients with hyponatremia that we encountered was comparable to frequency documented in earlier studies like one carried out in Agha Khan University Hospital Karachi by Bibi et al. in which 865 patients were enrolled. Out of these, 405 (46.8\%)patients had hyponatremia on admission while $240(27.7 \%)$ patients acquired hyponatremia during a hospital stay. ${ }^{9}$
In our study, more males suffered from hyponatremia as compared to females $(66.67 \%$ vs $33.23 \%)$. These results were consistent with the results reported earlier in a study done in Winthrop University Hospital Newyork USA by Nair et al, which showed a male predominance among hyponatremic admitted with pneumonia being 32 (59.25\%) out of total 54 patients. ${ }^{7}$ However, there was no difference found in patients with hyponatremia $<5$ years of age as compared to above 5 years of age.

In our study $9(69.23 \%)$ of the patients suffering from acute bronchiolitis suffered from hyponatremia. Although this number is very large in a given diagnosis, yet is consistent with other studies including one done in the university of Connecticut USA by Seifert et al, who documented that 43 (73\%) patients out of a total 59 admitted with acute bronchiolitis developed hyponatremia. ${ }^{5}$ Hyponatremia adds to the severity of bronchiolitis. The study conducted at the University of Connecticut USA by Steifert et al, also showed that hyponatremic patients with acute bronchiolitis required mechanical ventilation more, 38 (88\%) as compared to patients with normal sodium levels. The average length of stay was also greater as compared to the patients with normal sodium levels $(209 \pm$ $137 \mathrm{hrs}$ vs $130 \pm 85 \mathrm{hrs}$ ) as well as the mortality. ${ }^{5}$

Sixty-one patients (75.25\%) in our study suffered from pneumonia. More than half of the patients who had pneumonia also had hyponatremia (58\%). The recent regional studies carried out in Nepal by Tamrakar et al. documented hyponatremia in $40(80 \%)$ out of a total of 50 patients suffering from pneumonia. ${ }^{13}$ Pneumonia is the leading cause of mortality in our part of the world. Hyponatremia in pneumonia adds to the severity of pneumonia. Hyponatremia has also been studied as a prognostic factor in pneumonia and a statistically significant relationship had been found $(p=$ 0.002) in a study conducted recently in Nepal by Tamrakar et al. ${ }^{13}$ Hyponatremia in pneumonia is also associated with strongly positive inflammatory biomarkers, longer hospitalizations and prolong days of fever as shown in Sakellaropoulou et al, in the Aristotle University of Thessaloniki conducted on total 54 patients admitted in ICU and reported that there was a significant correlation between the value of serum sodium at admission and erythrocyte sedimentation rate $(p=0.02)$. Furthermore, CRP value and leukocyte count were correlated with admission value of sodium in serum $\left(p=0.002\right.$ and $p=0.006$ respectively).$^{12}$ 


\section{Hyponatremia as Prognostic Indicator in RTI}

In our study, the overall mortality in lower respiratory tract infections was found to be 17 (18.25\%) in PICU. The mortality in patients with normal sodium levels was found to be $3(13.3 \%)$. The mortality in hyponatremic patients was found to be significantly higher $(p$-value $=0.046)$ at $27 \%$. Hyponatremia has been studied as an independent risk factor for mortality in pediatric intensive care units in various studies, ${ }^{17-23}$ as the one carried out in India by Sachdev et al, documenting prolonged mechanical ventilation in hyponatremiamics compared to normonatremics ( $5.8 \pm 5.7$ vs 2.6 \pm 4.1 ). Although the rate of mechanical ventilation was higher in patients with low sodium levels as compared to patients with normal sodium levels (34\% vs $17.7 \%$ ) our study did not find any significant relation between the serum sodium levels and mechanical ventilation $(p=0.100)$. Similarly, there was no significant association between the serum sodium levels and length of PICU stay found in our study $(p=0.301)$. The risk of mortality subsequently reduces if hyponatremia is carefully managed in an intensive care setting, a wellrecognized fact the importance of which cannot be over-emphasized in the pediatric intensive care unit.

\section{CONCLUSION}

There was a significant association of hyponatremia with mortality in a pediatric intensive care setting in children with lower respiratory tract infections. This makes monitoring of sodium levels in lower respiratory infections an important parameter and timely correction is warranted if sodium levels are found to be low.

\section{Conflict of Interest: None.}

\section{Authors' Contribution}

NH: Manuscript writing, data collection. MFS: Literature review, data analysis. QZ: Data analysis, methodology.

HN: Manuscript writing.

\section{REFERENCES}

1. Channawar KS, Deshmukh N, Prasad VS. Correlation of hyponatraemia in children with lower respiratory tract infection-an institutional observational study. J Evol Med Dent Sci 2016; 5(88): 6533-6536.

2. Ventre K, Haroon M, Davison C. Surfactant therapy for bronchiolitis in critically ill infants. Cochrane Database Syst Rev 2006; 3(1): 005150.

3. Tazinya AA, Halle-Ekane GE, Mbuagbaw LT, Abanda M, Atashili J, Obama MT. Risk factors for acute respiratory infections in children under five years attending the Bamenda Regional Hospital in Cameroon. BMC Pulm Med 2018; 18(1): 7-12.

4. Zieg J. Pathophysiology of hyponatremia in children. Front Pediatr 2017; 5(2): 213-218.

5. Seifert ME, Welak SR, Carroll CL. Hyponatremia is associated with increased severity of disease in critically ill children with bronchiolitis. Intern J Clin Med 2010; 1(2): 37-42.
6. Del Castillo BT, de León EGR, García AR, López PV, Navarro MCM, Pardillo RM. Association between moderate-severe bronchiolitis and syndrome of inappropriate antidiuretic hormone secretion in emergency departments. Hosp Pediatr 2015; 5(7): 385-389.

7. Nair V, Niederman MS, Masani N. Hyponatremia in communityacquired pneumonia. Am J Nephrol 2007; 27(2): 184-190.

8. Hasegawa K, Stevenson MD, Mansbach JM, Schroeder AR, Sullivan AF, Espinola JA, et al. association between hyponatremia and higher bronchiolitis severity among children in the ICU with bronchiolitis. Hosp Pediatr 2015; 5(7): 385-389.

9. Bibi S, Bibi S, Gilani SYH, Shah SRA, ul Haq A, Billo AG. Frequency of hospital-acquired hyponatremia in a pediatric tertiary care setting. J Ayub Med Coll Abbottabad 2015; 27(3): 560-563.

10. Das A, Sil A, Biswas S, Gupta AK. Serum Electrolyte Level As A Marker Of Morbidity In Critically Sick Children: A Study From A Rural Tertiary Care Hospital. Int J Sci Res 2019; 8(2): 1-2.

11. Parikh A, Parikh T. Assessment of Hyponatremia in Children Admitted at Pediatric Intensive Care Unit of Gujarat Adani Institute of Medical Science, Bhuj, Kutch. Pediatr Educ Res 2017; 5(2,3): 3988-3992.

12. Sakellaropoulou A, Hatzistilianou M, Eboriadou M, Athanasiadou-Piperopoulou F. Hyponatraemia in cases of children with pneumonia. Arch Med Sci 2010; 6(4): 578-582.

13. Jha CB, Tamrakar A. Assessment of Hyponatremia in Pneumonia in Children. Birat J Heal Sci 2018; 3(3): 542-547.

14. Tagarro A, Martín, Del-Amo N, Sanz-Rosa D, Rodríguez M, Galán JC. Hyponatremia in children with pneumonia rarely means SIADH. Paediatr Child Health 2018; 23(7): 126-133.

15. Couriel J. Assessment of the child with recurrent chest infections. Br Med Bull 2002; 61(1): 115-132.

16. Kyriacou A, Zavros G. Hyponatremia and the syndrome of in appropriate antidiuretic hormone secretion Old topic, new perspectives. Arch Hell Med Ellenikes Iatrikes 2018; 35(6): 842-847.

17. Filbrun AG, Lahiri T, Ren CL. Clinical features and complications of cystic fibrosis. in: Handbook of Cystic Fibrosis. Springer; 2016, [Internet] Available from: https://www.springer.com/ gp/book/9783319325026

18. Peri A. Morbidity and mortality of hyponatremia. In: Disorders of fluid and electrolyte metabolism. karger Publishers 2019; 52(1): 36-48.

19. Corona G, Giuliani C, Verbalis JG, Forti G, Maggi M, Peri A. Hyponatremia improvement is associated with a reduced risk of mortality: evidence from a meta-analysis. PLoS One 2015; 10(4): e0124105.

20. Sachdev A, Pandharikar N, Gupta D, Gupta N, Gupta S, Venkatraman ST. Hospital-acquired hyponatremia in the pediatric intensive care unit. Indian J Crit care Med peer-reviewed, Off Publ Indian Soc Crit Care Med 2017; 21(9): 599-605.

21. WHO. Integrated management of childhood illness (IMCI) (revised). Geneva, World Health Organization/The United Nation Children's Fund (UNICEF), 2014, [Internat] Available from: https://apps.who.int/iris/handle/10665/44398 (Accessed on June 20,2018)

22. Schroeder AR, Mansbach JM. Recent evidence on the management of bronchiolitis. Current Opinion Pediat 2014; 26(3): 328-332.

23. Rifai N, Horvath AR, Wittwer CT, eds. Tietz Textbook of Clinical Chemistry and Molecular Diagnostics. 6th ed. New York, NY: Elsevier; 2018, [Internet] Available from:https://www.elsevier. com/books/tietz-textbook-of-clinical-chemistry-and-moleculardiagnostics/rifai/ 978-0-323-35921-4 